\title{
PENGARUH KUAT ARUS LISTRIK PENGELASAN TERHADAP KEKERASAN LAPISAN LASAN PADA BAJA ASTM A316
}

\author{
Dody Prayitno ${ }^{1}$, Harry Daniel Hutagalung ${ }^{2}$, Daisman P.B. Aji ${ }^{3}$ \\ Teknik Mesin Universitas Trisakti \\ Email: dodyprayitno@trisakti.ac.id
}

\begin{abstract}
Seat and plug are components of control valve that are always in friction contact. The plug usually wears out. One of the efforts in battling this wear is hardfacing, a process of cladding the base metal to increase its surface hardness using SMAW. This research is aimed to investigate the effect of welding current on weld surface hardness. The experiments used stainless steel (ASTM A316) for the plug materials and Stellite 6, which was an electrode with $3.2 \mathrm{~mm}$ in diameter, for the filler metal. Flat welding position was used. The current was varied from $120 \mathrm{~A}$ to $140 \mathrm{~A}$ and then to $160 \mathrm{~A}$. Results of the hardness tests done on the weld surface show that when the welding current was increased from $120 \mathrm{~A}$ to $140 \mathrm{~A}$, it increased the surface hardness from $465 \mathrm{HV}$ to $514.7 \mathrm{HV}$. Subsequent current increase from 140 A to 160 A decreased the surface hardness from 514.7 HV to $423 \mathrm{HV}$.
\end{abstract}

Keywords: SMAW, stellite, surface hardness, current capacity, weld, heat-affected zone

\begin{abstract}
ABSTRAK
Sebuah control valve memiliki seat dan plug yang selalu bergesekan, sehingga plug sering mengalami keausan. Salah satu upaya untuk mengurangi keausan dengan cara hardfacing, yaitu penambahan material (cladding) pada logam induk dengan maksud meningkatkan kekerasan permukaan. Penambahan material dapat dilakukan dengan pengelasan SMAW, dimana salah satu parameter yang berpengaruh terhadap kekerasan lapisan lasan adalah besarnya arus listrik pengelasan. Tujuan penelitian adalah untuk mengetahui pengaruh arus listrik pengelasan terhadap kekerasan lapisan lasan. Metode penelitian dimulai dengan menyiapkan baja tahan karat (ASTM A316) digunakan sebagai material plug dan material stillite 6 sebagai material penambah yang berupa berupa elektroda berdiameter $3.2 \mathrm{~mm}$. Pengelasan dengan posisi datar dengan variasi arus pengelasan adalah 120 A, 140 A dan 160 A. Hasil pengujian kekerasan menunjukkan bahwa peningkatan arus lasan dari 120 A ke 140 A meningkatkan kekerasan permukaan lasan dari 465 HV menjadi 514.7 HV. Peningkatan arus lasan berikutnya dari 140 A ke 160 A menyebabkan terjadinya penurunan kekerasan permukaan lasan dari 514.7 HV menjadi 423 HV.
\end{abstract}

Kata kunci: las SMAW, stellite 6, kekerasan, kuat arus listrik, pengelasan, heat-affected zone

\section{PENDAHULUAN}

Pengaturan aliran fluida pada suatu instalasi pipa dilakukan oleh sebuah control valve seperti pada Gambar 1. Pada sebuah control valve terdapat seat dan plug yang selalu bergesekan. Plug sering mengalami keausan atau tererosi. Salah satu upaya untuk mengurangi keausan lakukan hardfacing (Linconn Electric Company, 2014). Hardfacing merupakan penambahan material pada logam induk dengan maksud meningkatkan kekerasan permukaan base metal. Penambahan material dapat dilakukan dengan pengelasan SMAW. Arus listrik merupakan salah satu parameter yang berpengaruh terhadap kekerasan weld metal. Peningkatan arus listrik akan meningkatkan kekerasan weld metal atau lapisan lasan. Dengan arus pengelalsan sebesar 80 Ampere, kekerasn weld metal pada sambungan ST 37 dan SS 304 adalah 92.5 HRB (Yogi Nasrul, 2016). Peningkatan arus ampere dari 110 A ke 130 A akan meningkatkan kekerasan weld metal dari 105 H ke 140 HB (Ridway Balaka, 2016).

Tujuan penelitian adalah untuk mengetahui pengaruh arus listrik pengelasan terhadap kekerasan lapisan lasan. Metode penelitian dimulai dengan menyiapkan baja tahan karat (ASTM A316) digunakan sebagai 
material plug dan material stillite 6 sebagai material penambah. Stillite 6 berupa elektroda berdiameter $3.2 \mathrm{~mm}$. Pengelasan dengan posisi datar digunakan sebagai proses cladding. Variasi arus pengelasan adalah $120 \mathrm{~A}, 140 \mathrm{~A}$ dan $160 \mathrm{~A}$. Pengujian kekerasan dilakukan permukaan lapisan lasan.

Hardfacing merupakan penambahan material pada logam induk dengan maksud meningkatkan kekerasan permukaan base metal. Penambahan material bisa dilakukan dengan pengelasan SMAW. Beberapa keuntungan dari penggunaan pelapisan permukaan hardfacing (Davis, 1993) adalah hasil logam lasnya mempunyai ketahanan yang tinggi terhadap aus dan memungkinkan digunakan pada semua kondisi yang mengalami aus.

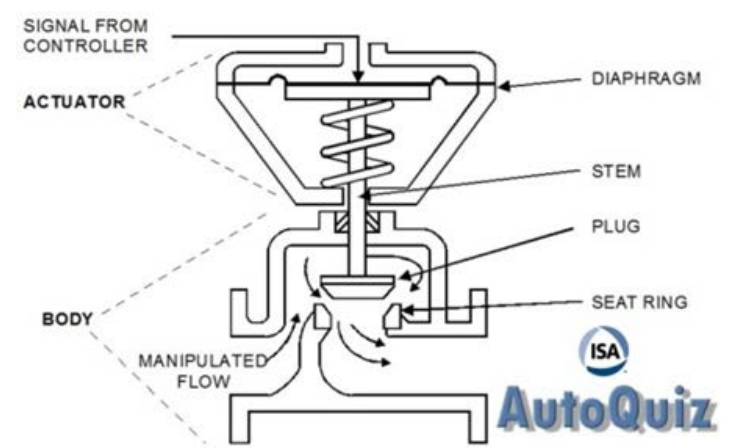

Gambar 1. Ilustrasi sebuah control valve (ISA Interchange, 2017)

Baja tahan karat merupakan kelompok dari baja paduan yang mempunyai sifat atau karakterisasi khusus. Ciri umum dari baja tahan karat adalah kadar kromium (Cr) yang tinggi tidak kurang dari 16\%. Kromium (Cr) dengan besi $(\mathrm{Fe})$ dalam baja membentuk larutan padat dan solid. Sifat utama dari baja tahan karat adalah ketahanannya yang tinggi terhadap korosi, disamping memiliki sifat ketangguhan yang tinggi, mudah dibentuk, dan mempunyai sifat mampu las yang tinggi. Spesifikasi baja tahan karat stainless steel yang digunakan dapat dilihat pada Tabel 1.
Tabel 1. Spesifikasi material Stainless Steel 316

\begin{tabular}{|c|c|c|c|c|c|c|c|c|}
\hline$\%$ & C & $\begin{array}{c}\mathrm{M} \\
\mathrm{n}\end{array}$ & $\mathrm{Si}$ & $\mathrm{P}$ & $\begin{array}{l}\mathrm{C} \\
\mathrm{r}\end{array}$ & $\begin{array}{c}\mathrm{M} \\
\mathrm{o}\end{array}$ & $\begin{array}{c}\mathrm{N} \\
\mathrm{i}\end{array}$ & $\mathrm{N}$ \\
\hline Min. & - & - & - & - & $\begin{array}{l}1 \\
6\end{array}$ & 2 & $\begin{array}{l}1 \\
0\end{array}$ & - \\
\hline Max & $\begin{array}{l}0.0 \\
8\end{array}$ & 2 & $\begin{array}{l}0.04 \\
5\end{array}$ & $\begin{array}{l}0.0 \\
3\end{array}$ & $\begin{array}{l}1 \\
8\end{array}$ & 3 & $\begin{array}{l}1 \\
4\end{array}$ & $\begin{array}{l}0 . \\
1\end{array}$ \\
\hline
\end{tabular}

Material elektroda stellite 6 merupakan jenis baja tahan aus HSLA (High Strength Low Alloy). Baja ini tergolong ke dalam jenis material baru sehingga tidak memiliki equivalent di dalam ASTM ataupun standar material lainnya. Material elektroda stellite 6 ideal untuk aplikasi pada industri pertambangan, industri semen, pembuatan baja, dan mesin-mesin dan komponen dari valve. Jenis material ini sesuai untuk semua tipe abrasi, geser atau impak pada media kering atau basah, termasuk juga abrasi temperatur tinggi (hingga $3500^{\circ} \mathrm{C}$ ). kekerasan baja ini sekitar 380 -490 HV. Komposisi kimia elektroda stellite 6 ditampilkan pada Tabel 2 (Delero, 2017).

Tabel 2. Spesifikasi elektroda stellite 6

\begin{tabular}{cccccccc}
\hline$\%$ & $\mathrm{Cr}$ & $\mathrm{W}$ & $\mathrm{C}$ & $\mathrm{Ni}$ & $\mathrm{Mo}$ & $\mathrm{Fe}$ & $\mathrm{Si}$ \\
\hline Min. & - & 4 & - & - & - & - & - \\
Max. & 30 & 5 & 1.2 & 3 & 1 & 3 & 2 \\
\hline
\end{tabular}

Shielded Metal Arc Welding adalah proses pengelasan manual dimana busur listrik tercipta diantara benda kerja dan elektroda termakan yang dibungkus terak. Proses ini menggunakan dekomposisi terak guna menciptakan gas pelindung dan menyediakan elemen terak untuk melindungi lelehan logam lasan. Proses pengelasan dan diagram sirkuit SMAW ditunjukkan pada Gambar 2. Peralatan SMAW meliputi sumber daya, kabel elektroda, kabel kerja, pemengang elektroda, penjepit, dan elektroda. Elektroda dan sistem kerja adalah bagian dari rangkaian listrik. 


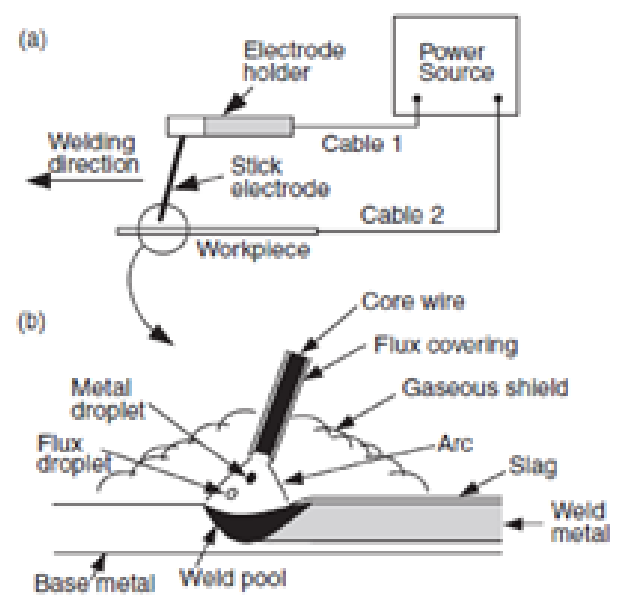

Gambar 2. Elektroda dan sistem kerja SMAW (Suratman, 2001)

Besarnya arus pengelasan yang diperlukan tergantung pada diameter elektroda, tebal bahan yang dilas, jenis elektroda yang digunakan, geometri sambungan, diameter inti elektroda, posisi pengelasan. Daerah las mempunyai kapasitas panas tinggi maka diperlukan arus yang tinggi. Arus las merupakan parameter las yang langsung mempengaruhi penembusan dan kecepatan pencairan logam induk. Makin tinggi arus las makin besar penembusan dan kecepatan pencairannya.

Besar arus pada pengelasan mempengaruhi hasil las bila arus terlalu rendah maka perpindahan cairan dari ujung elektroda yang digunakan sangat sulit dan busur listrik yang terjadi tidak stabil. Panas yang terjadi tidak cukup untuk melelehkan logam dasar, sehingga menghasilkan bentuk rigi-rigi las yang kecil dan tidak rata serta penembusan kurang dalam. Jika arus terlalu besar, maka akan menghasilkan manik melebar, butiran kecil, penetrasi dalam, serta penguatan matrik las tinggi (Suratman, 2001). Kekuatan tarik meningkat dengan meningkatnya arus pengelasan dari 100 A ke 160 A sebagaimana hasil penelitian Joko Santoso (2006) dan Trinova Budi Santoso (2015).

Kecepatan pengelasan sangat sangat dipengaruhi oleh besar kuat arus yang dipakai, jenis elektroda, diameter inti elektroda, metal yang akan dilas, dan bentuk geometri sambungan. Kecepatan pengelasan yang tinggi akan berdampak pada berkurangnya penetrasi, sehingga kekuatan sambungan menurun, disamping mengakibatkan masukan panas yang diterima persatuan panjang akan menjadi lebih kecil. Kecepatan pengelasan yang tidak juga berdampak terjadinya pendinginan yang cepat sehingga dapat memperkeras daerah terpengaruh panas. Kecepatan las yang terlalu tinggi akan berpengaruh pada bentuk manik las yang menyempit dan penguatan manik yang rendah. Selain itu dapat merubah sifat mekanik daerah lasan yang berupa naiknya kekuatan tarik dan perpanjangan yang rendah (Wiryosumarto, 2008).

Pengaruh kecepatan pengelasan dapat dilihat pada Tabel 3. Peningkatan kecepatan pengelasan menurunkan kekuatan tarik lasan (Mohruni, 2013).

Tabel 3. Pengaruh kecepatan pengelasan terhadap kekuatan tarik [11]

\begin{tabular}{ccccccccc}
\hline No & \multicolumn{2}{c}{ Spesimen } & L0 & L1 & $\varepsilon$ & oy & ou & of \\
\hline & Kuat Arus & Kecepatan & $(\mathrm{mm})$ & $(\mathrm{mm})$ & $(\%)$ & Mpa & Mpa & Mpa \\
\hline 1 & $80 \mathrm{~A}$ & $0.15 \mathrm{~cm} / \mathrm{dtk}$ & 200 & 245 & 22.5 & 2.942 & 4.707 & 3.8 \\
\hline 2 & $80 \mathrm{~A}$ & $0.35 \mathrm{~cm} / \mathrm{dtk}$ & 200 & 247 & 23.5 & 2.905 & 4.499 & 3.665 \\
\hline
\end{tabular}

\section{METODE}

Penelitian ini menggunakan metode eksperimen dengan diagram alir penelitian seperti pada Gambar 3. Penelitian dimulai dengan menyiapkan materail plug yaitu baja tahan karat ASTM A316. Sampel plug berbentuk selinder berdiameter $2 \mathrm{~cm}$ dan tinggi $1.5 \mathrm{~cm}$. Permukaan sampel plug kemudian dibersihkan dari kotoran dan oli yang melekat.

Material elektroda adalah material yang digunakan untuk melapis permukaan material plug. Material elektroda adalah stellite 6. Proses cladding dilakukan dengan metode pengelasan (SMAW). Variasi arus pengelasan yaitu $120 \mathrm{~A}$, 140 A dan 160 A.. Posisi pengelasan adalah datar (flat). Uji kekerasan mikrovickers dilakukan pada permukaan lapisan las dan material plug sebagai base metal (Gambar 4). Pengujian kekerasan dilakukan pada 3 titik lokasi untuk setiap sampel dengan jarak interval antar titik 0.5 $\mathrm{cm}$. 


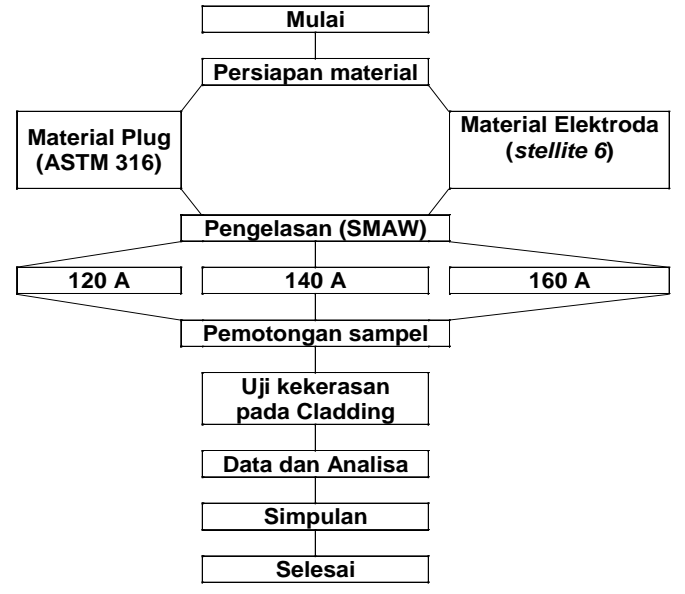

Gambar 3. Diagram Alir Penelitian

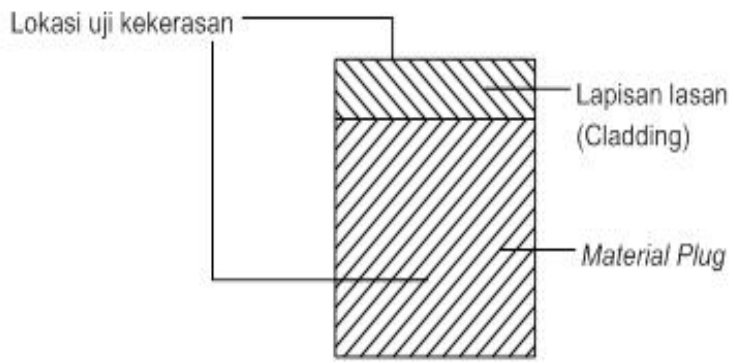

Gambar 4. Ilustrasi Lokasi Uji Kekerasan

\section{HASIL DAN PEMBAHASAN}

Gambar 5 memperlihatkan lokasi pengujian kekerasan mikrovicker pada lapisan lasa. Hasil uji kekerasan pada lapisan lasan dan material plug terlihat pada tabel 10 . Hasil ratarata kekerasan untuk Lapisan lasan dan material plug disajikan pada Gambar 6.

Nilai rata-rata kekerasan lapisan lasan dengan arus pengelasan sebesar 120 A dan 140 A masing - masing adalah $465 \mathrm{HV}$ dan 514.7 HV. Bila arus pengelasannya 160 A maka nilai rata-rata kekerasan lapisan lasan adalah $423 \mathrm{HV}$. Peningkatan arus pengelasan dari 120 A menjadi 140 A akan menaikkan kekerasan lapisan lasan dari $465 \mathrm{Hv}$ menjadi $514.7 \mathrm{H}$ atau naik 11 persen. Penambahan arus pengelalsan berikutnya dari 140 A ke 160 A menyebabkan kekerasan lapisan las menurun dari 514.7 HV menjadi $423 \mathrm{HV}$ atau turun sebesar 18 persen.

Nilai rata-rata kekerasan material plug akibat pengelasan dengan arus $120 \mathrm{~A}$ dan $140 \mathrm{~A}$ masing masing adalah 259.7 HV dan 242.3 HV. Nilai rata-rata kekersan base metal dengan arus pengelasan 160 A adalah $252 \mathrm{HV}$. Peningkatan arus pengelasan dari 120 A ke 140 A menyebabkan nilai kekerasan base metal menurun dari 259.7 HV ke 242.3 H atau turun 6.7 persen. Penurunan sebesar 6.7 persen dapat dikatakan tidak signifikan. Perubahan arus pengelasan berikutnya dari 140 A ke 160 A menyebabkan kekerasan base metal meningkat secara dari 242.3 HV menjadi $252 \mathrm{HV}$ atau naik 4 persen. Peningkatan sebesar 4 persen dapat diabaikan. Peningkatan arus pengelasan dari 120 A menjadi 140 A hingga mencapai 160 A tidak berdampak pada nilai kekerasan base metal. Nilai rata-rata kekerasan base metal realtif tetap sekitar 242-259.7 HV

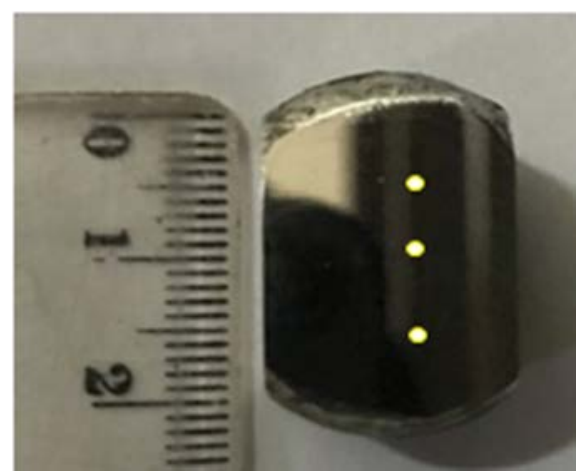

Gambar 5. Tampak atas lokasi pengujian kekerasan pada lapisan lasan

Tabel 10 Hasil uji Kekerasan mikrovicker (HV)

\begin{tabular}{ccccc}
\hline Lokasi & No & \multicolumn{3}{c}{ Arus pengelasan (Ampere) } \\
& & 120 & 140 & 160 \\
\hline \multirow{2}{*}{$\begin{array}{c}\text { Lapisan } \\
\text { lasan }\end{array}$} & 2 & 454 & 530 & 395 \\
& 3 & 464 & 481 & 436 \\
& $\begin{array}{c}\text { Rata- } \\
\text { rata }\end{array}$ & 465 & 514.7 & 423 \\
& 1 & 253 & 250 & 245 \\
Material & 2 & 263 & 243 & 247 \\
plug & & & & \\
& 3 & 264 & 234 & 264 \\
& Rata- & 259.7 & 242.3 & 252 \\
& rata & & & \\
\hline
\end{tabular}

Penambahan material stellite 6 sebagai lapisan las dengan metode pengelasan mampu meningkatkan kekerasan base metal secara 
signifikan bergantung pada arus pengelasan yang digunakan. Pengaplikasian arus pengelasan sebesar 12 Ampere mampu meningkatkan kekerasan base metal sebesar 80 persen. Sementara penggunaan arus pengelasan sebesar
140 A menyebabkan kekerasan base metal meningkat 110 persen. Penambahan arus pengelasan menjadi 160 A menyebabkan kekerasan base mental naik 70 Persen

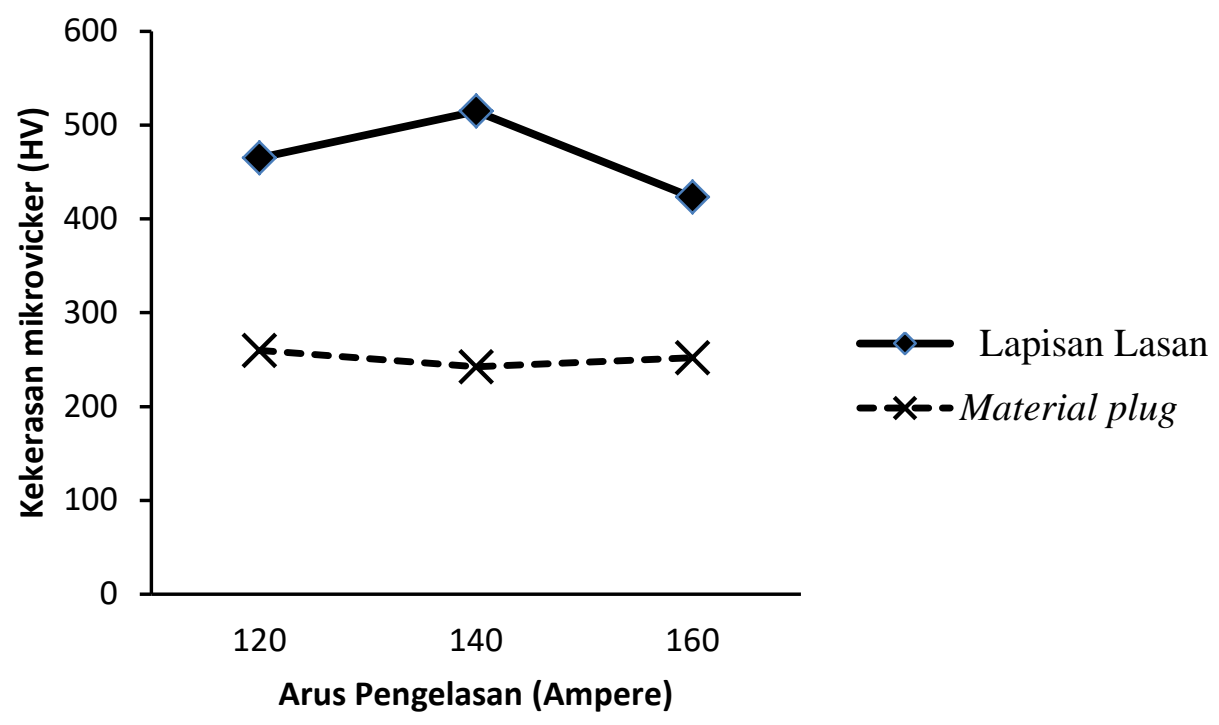

Gambar 6. Nilai rata- rata kekerasan pada lapisan lasan dan material plug

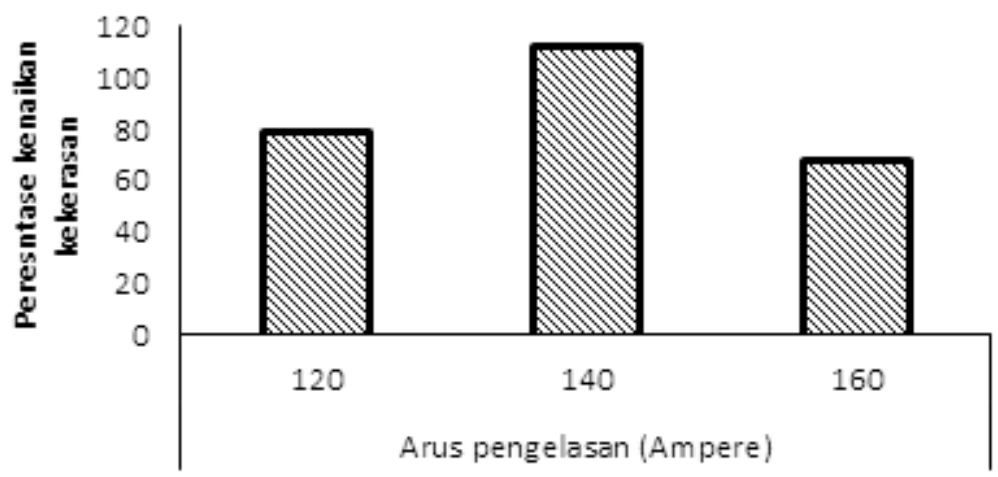

Gambar 7. Persentase kenaikan kekerasan dari base metal ke lapisan lasan

\section{SIMPULAN}

Berdasarkan penyajian data dan pembahasan di atas maka dapat disimpulkan bahwa: 1) Penambahan material stellite 6 dengan menggunakan metode pengelasan SMAW mampu meningkatkan kekerasan permukaan material plug, 2) Peningkatan arus pengelasan dari 120 A ke 140 A mampu meningkatkan kekerasan dari 465 H ke 514.7 HV, 3)
Penambahan arus pengelasan dari 140 A ke 160 A akan menurunkan kekerasan dari 51.47 HV ke 423 HV, dan 4) Kekerasan tidak berubah dengan meningkatkan arus pengelasan dari 120 A ke $160 \mathrm{~A}$.

\section{DAFTAR RUJUKAN}

Linconn Electric Company (2014), "Hardfacing product and procedure Selection,” Bucklet, 
diakses tanggal 26 November 2017 dari http://www.lincolnelectric.com

ISA Interchange (2017), “Autoquiz20150612”, diakses tanggal 26 Oktober 2017 dari https://automation.isa.org/2015/06/what-isthe-process-of-grinding-the-plug-and-seat-ofa-valve-called/autoquiz20150612/

M. Yogi Nasrul L., Heru Suryanto, Abdul Qolik (2016), “ Pengaruh Variasi Arus Las Smaw Terhadap Kekerasan Dan Kekuatan Tarik Sambungan Dissimilar Stainless Steel 304 Dan St 37, Jurnal Teknik Mesin, No. 1, April 2016, Hal 1-12, diakses tanggal 10 novemer 2017 dari https://www.researchgate.net/publication/315 779962_PENGARUH_VARIASI_ARUS_L AS_SMAW_TERHADAP_KEKERASAN_ DAN_KEKUATAN_TARIK_SAMBUNGA N_DISSIMILAR_STAINLESS_STEEL_304 _DAN_ST_37

Ridway Balaka, Abd. Kadir, Dedi Saputra Tolantomo(2016), “Analisis Pengaruh Arus Pengelasan Pada Sudut Elektroda $70^{\circ}$ Terhadap Sifat Kekerasan Dan Struktur Mikro Baja Karbon Rendah Menggunakan Jig Welding”, Jurnal Enthalpy - E-ISSN :25028944, Vol. 2, No.2 November 2016 hal 50-55 - diakses tanggal 10 novemver 2047 dari http://www.Ojs.Uho.Ac.Id/Index.Php/Enthalp y/Article/Download/1775/1256.

American Society of Materials International (1993), ASM Handbook Vol. 8: Mechanical Testing and Evaluation, ASM International, United State ofAmerica.
Davis, J.R., Hardfacing (1993), Weld Cladding, and Dissimilar Metal Joining. ASM Handbook Vol. 6: Welding, Brazing and Soldering (pp.1967- 2061). ASM International.

Delero (2017), “STELLITE TM 6 ALLOY,” techincal data diakses tanggal 11 november 2017 dari https://deloro-testbed.squarespace.com/s/Deloro-MDSStellite6-rev00.pd

Suratman, M. (2001),” Teknik Mengelas Asetilen, Brazing dan Busur Listrik, Pustaka Grafika, Bandung..

Joko Santoso, (2006), ” Pengaruh Arus Pengelasan Terhadap Kekuatan Tarik Dan Ketangguhan Las Smaw Dengan Elektroda E7018”, Skripsi, Universitas Negeri Semarang,

Trinova Budi Santoso, Solichin, Prihanto Tri Hutomo, (2015), “ Pengaruh Kuat Arus Listrik Pengelasan Terhadap Kekuatan Tarik Dan Struktur Mikro Las Smaw Dengan Elektroda E7016, Jurnal Teknik Mesin, Tahun 23, No. 1, April 2015, Hal 59- 64

A. S. Mohruni, B. H. Kembaren, (2013) "Pengaruh Variasi Kecepatan Dan Kuat Arus Terhadap Kekerasan, Tegangan Tarik, Struktur Mikro Baja Karbon Rendah Dengan Elektroda E6013”, Jurnal Rekayasa Mesin Vol. 13 No. 1 Maret 2013, Hal 1-8,

Wiryosumarto, H dan Okumura, T, (2008) Teknologi Pengelasan Logam. PT. Pradnya Paramitha, Jakarta, 